\title{
Longevity adjustment of retirement age
}

The rise in longevity is exerting pressure on public finances with increases in
pension and elderly care Jensen, Professor of Economics at the Copenhage Business School, discusses in line with the average the significance of extending these models to encompass the variability associated with physical and mental disabilities across different socio-
economic groups. expenses. Svend E. Hougaard increasing life expectancy. His research also highlights

emographic ageing, resulting from Svend E. Hougaard Jensen, Professor of

rapidly increasing life expectancy Economics at the Copenhagen Business and decreasing birth rate, raise a number of economic challenges. this worldwide rise in longevity, not least among member countries of the Organisation for Economic Co-operation
and Development (OECD), puts pressure and Development (OECD), puts pressure on public finances with increases in

It is currently estimated that the life expectancy for a 65 year old will typically increase by a year every ten years. In an era of demographic ageing, producing retirement reform that maintains the living standards of both the retired and the working age population is both complex and challenging. Many countries rely on pay-as-you-go (PAYG) pension schemes where the current contributions of the working population cover the pension
payments for retirees. The sustainability payments for retirees. The sustainability of these systems is dependent on the When faced with an ageing population,

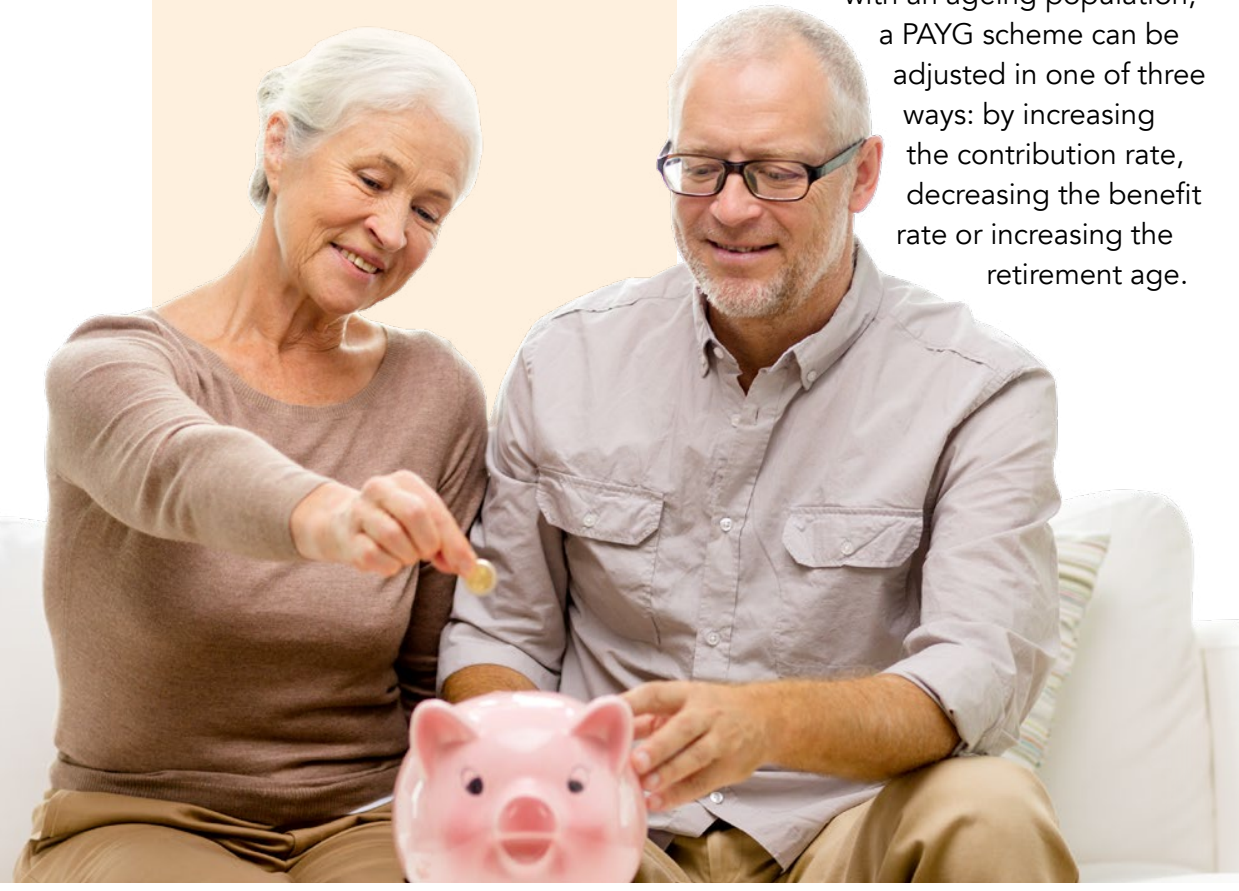
Research Centre (PeRCent), carries out changing demographics, and in particul the pension system. He explains that effectively redistribute income from workers to etistibste incoming pension benefits would have the opposite effect and redistribute incone from retirees to workers. The third alternative, increasing the retirement age, would expand the labour supply. with individuals working for longer, while simultaneously decreasing the number of retirees. Moreover, it would offset the effects of population ageing on PAYG pension systems by increasing the ratio

ONGEVITY INDEXATION

A decade has passed since Professor Hougaard Jensen published his first paper on the topic of linking pension age polife expectancy. What was at the time no retiostment of relevant than ever, as some countries choose to introduce inderation schemes so that their official pension age increases alongside rising life expectancy Professor Hougaard Jensen continues to work in this area and he notes that while longevity indexation can reduce the pressure on public finances as well as the labour market, such schemes are underpinned by the assumption that both the labour supply and employment will actually

DANISH RETIREMENT REFORM The Danish parliament, Folketinget, followed by a retirement reform in 2011. Subsequently, they have decided to Subsequently, they have decided to
increase the official pension age for early research into the economic effects of
A worldwide rise in longevity puts pressure on public finances with inc
and elderly care expenses.

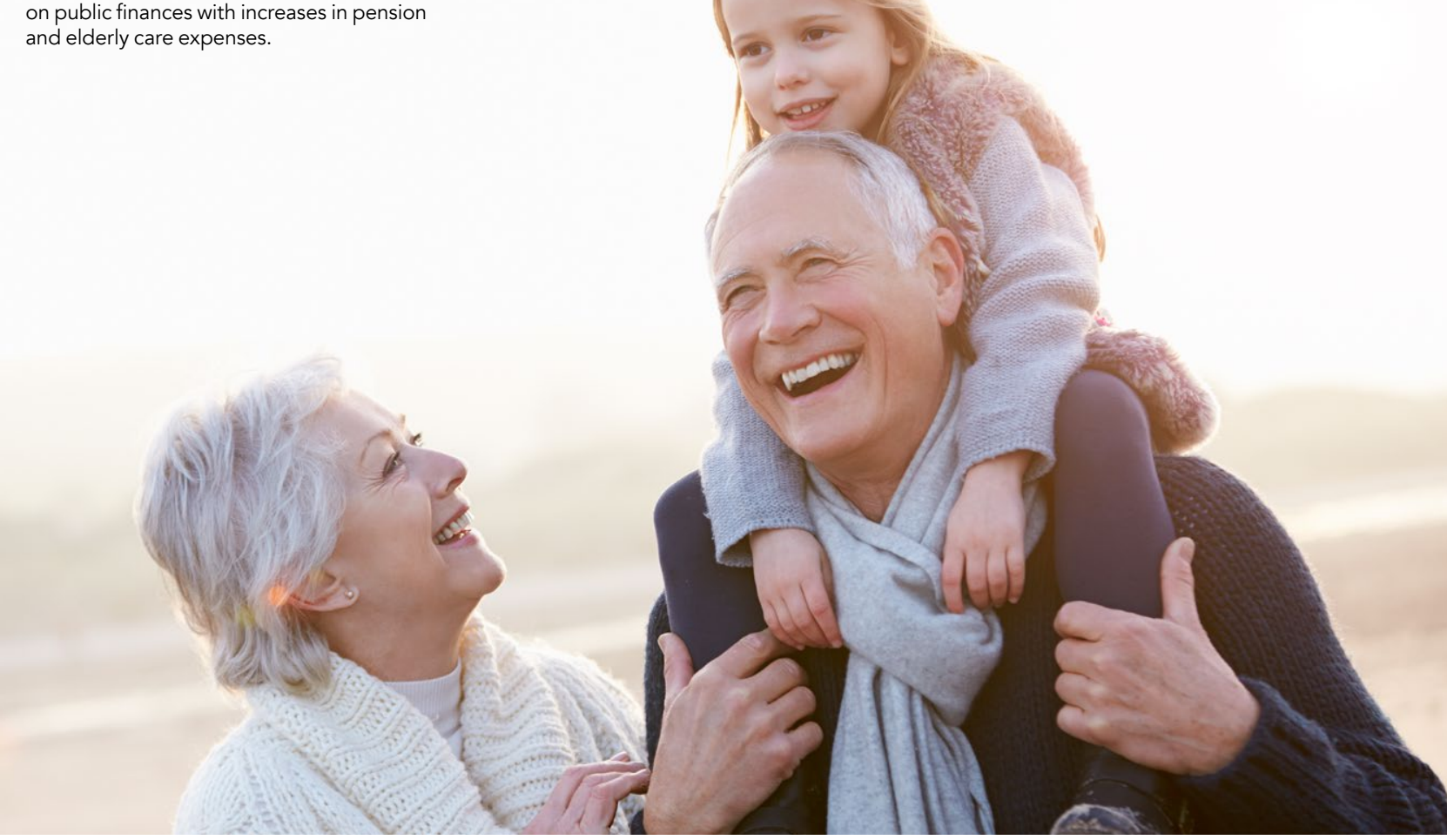

etirement and old-age pension from 2030 in line with longer life expectancy. to 68 years. From 2030 on, the pension age will increase concurrently with the average life expectancy of a 60-yea old. All changes must be agreed by a parliamentary majority and notified 15 years in advance. It is expected that this welfare agreement will reduce the pressure on both public finan

\section{AVERAGE MEASURES}

\section{These indexation schemes are based on} average measures of life expectancy and tirement age. In Denmark, as mentioned bove, the official pension age changes keeping with increases in average longevity. It is recognised, however, that life expectancy varies between men and women, high and low educated workers and high-income and low-income workers. Professor Hougaard Jensen warns that these average measures $c a$ hide a high degree of variability across different groups in society and advises that this variablity is taken into account When regulating pension age. Disabilities, both physical and mental, and a reduction in an individual's ability to work can vay economic and educationt socioeconomic and educational groups. For
It is currently estimated that the life expectancy for a 65 year old will typically increase by a year every ten years.

prone to health issues resulting from the physically demanding routine work that they have carried out over a long are likely to have experienced a longer education and a shoter working-life with less physically a sorer wo employm The impact of uniform changes in therefore differ significantly across these groups, exacerbating inequality among the elderly.

\section{EMPIRICAL EVIDENCE}

Analysis of OECD data provides empirica evidence that since 2003, the increase in remaining life expectancy for 65 year olds and retirement age have been virtually paralle.. Professor Hougaard intern advises that his should be signal 'heal why ageintion as while it may as changes in early retirement legislation or the business cycle.

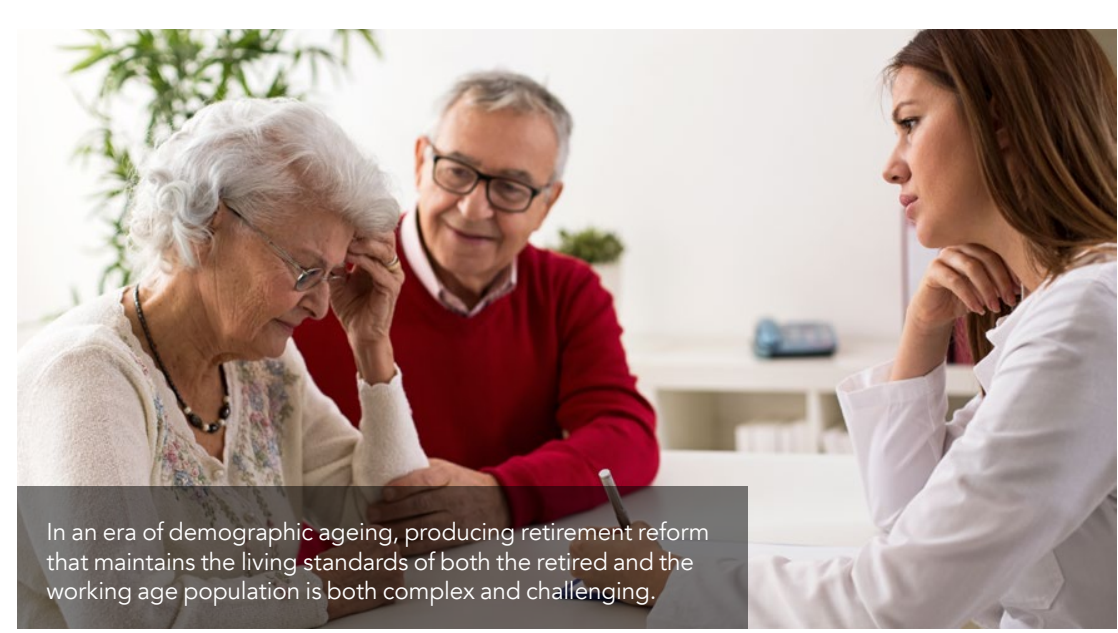
working-life, whereas white-collar work it may in fact result from other causes 


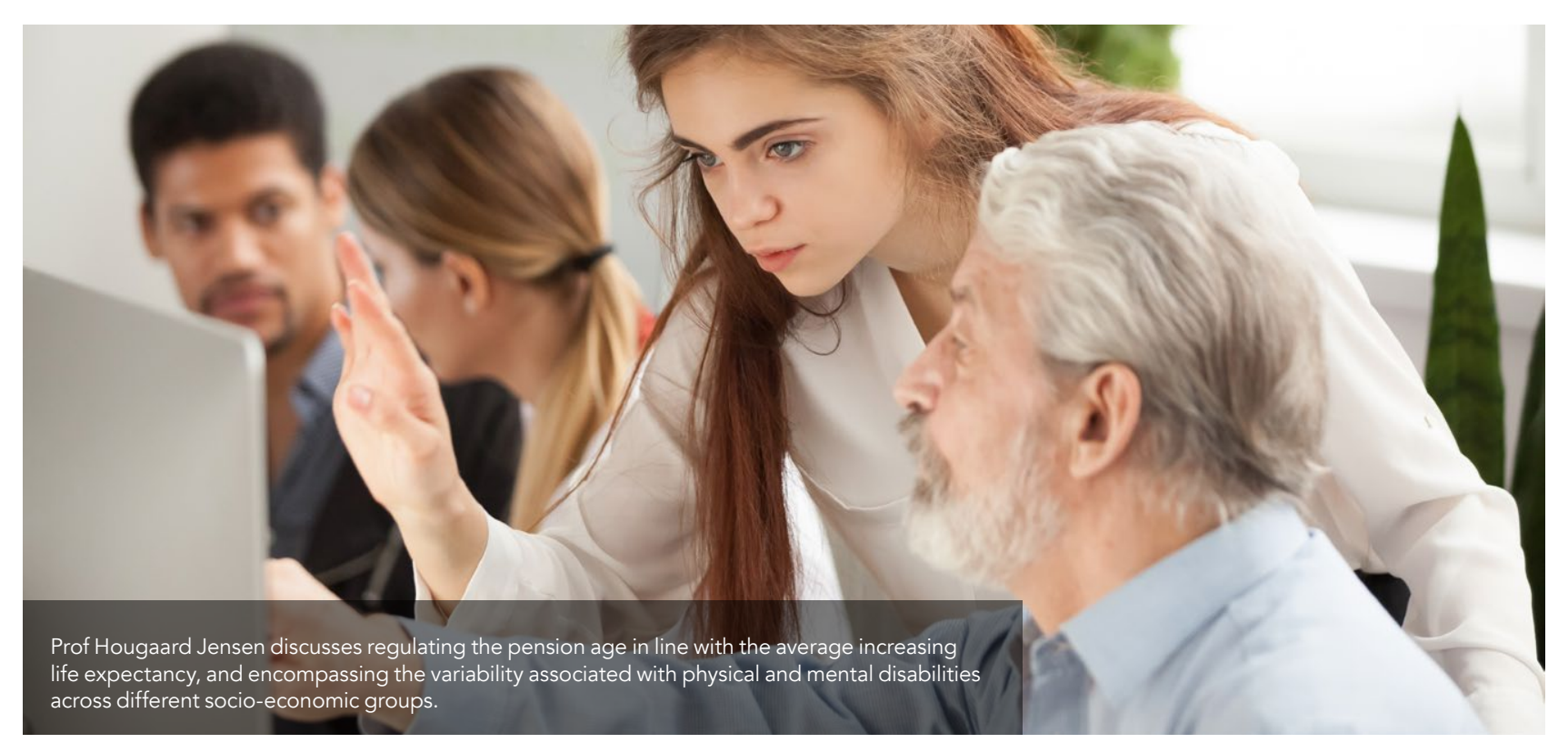

MODELLING INTRAGENERATIONAL EFFECTS developed a continuoustime mode to demonstrate the intra-generational effects of an unfunded pension scheme. Results show that, provided they reach pension age, groups with lower life expectancy pay the same amount into the PAYG scheme as those with higher life expectancy, but receive less during the pension period as they do not live as long. Modelling an increase in the pension age, to reflect the longevity of the higher life expectancy group, reveals the lower life expectancy group suffering a further drop in lifetime income as few of them live to reach the pension age, thus magn rying he negative effect for

Results from the model highlighted that the relative sizes of the lower life expectancy groups and the higher life expectancy groups within the population

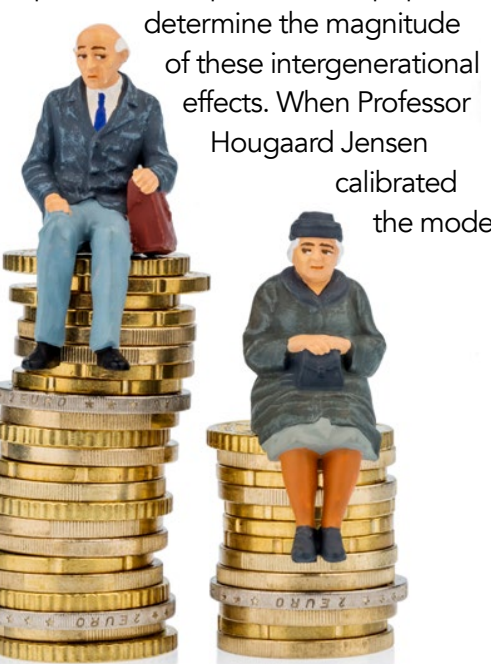

with input data based on the different life economic groups. He offers a number of expectancy of men and women, the results models that could implement this. One demonstrated that men suffered a 10 suggestion is to allow people to receive percent drop in the pension benefits they pension benefits before they reach the when compared with women participating official pension age, subject to means in the same scheme. A second calibration to start receiving pension benefits some

These average measures can hide a high degree of variability across different groups in society.

was carried out to examine the effects of years before they reach the official pension different socio-economic groups. Input age without means-testing. Professor data based on the life expectancy and Hougaard Jensen counsels that such income inequality of blue-collars workers public pensions should be underpinned vs. white-collar workers in Denmark, revealed a $13.8 \%$ drop in pension benefits the total pension benefits received by an of their retiement wherc white collar workers sharing the same pension scheme.

\section{POLICY IMPLICATIONS}

These findings can inform pension policies in countries where PAYG pension
schemes prevail. Professor Hougaard Jensen explains that the difference in life expectancies, between, for instance academics and blue-collar workers, could reach a critical level, thus establishing a need for differentiated pension ages. This would involve extending schemes that link the pension age to increases in mental disabilites actich pliffical and criticallycing such key welfare reforms longevity, which are currently based only on average figures, to incorporate the affected by the time they choose to retire.

Professor Hougaard Jensen believes that in countries that are experiencing population ageing, the introduction of a longevity-indexed pension age be kept on a sustainable track. It is population and the political majority support these schemes. He explains that "if the legitimacy and credibility critically depends on easier access to Ife expectancy and diminished (physical and mental) ability to work, then such be worth advocating". earlier pension age for citizens with lower

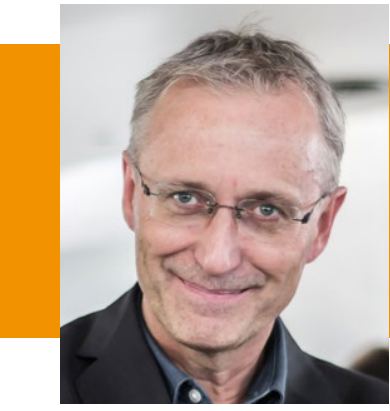

Behind the Research Svend E. Hougaard Jensen

E: shj.eco@cbs.dk T: $+4520757807 \quad$ W: https://sf.cbs.dk/sh

\section{Research Objectives}

Svend E. Hougaard Jensen's research explores monetary unification and fiscal policy in Europe; generational and macrocconomice fectic of banging demographics; structural reforms; and macroeconomic policy more gyi

\section{Detail}

Svend E. Hougaard Jensen

Department of Economics
Copenhagen Business School

Porcelærshaven 16A

DK-2000 Frederiksberg

Denmark

Bio

Svend E. Hougaard Jensen is Professor of Economics at Research Centre (PeRCent). Chair of Bruegel's Scientific Council and a Member of the Systemic Risk Council in Denmark. He holds an MSc (Econ) degree (University of Aarhus, DK), an MA (Econ) degree (University of Manchester,

\section{Funding}

The Pension Research Centre (PeRCent), which receives base funding from the Danish pension funds and Copenhagen

\section{Collaborator}

Professor Gylfi Zoega, Department of Economics, University Statistics, Birkbeck College, University of London

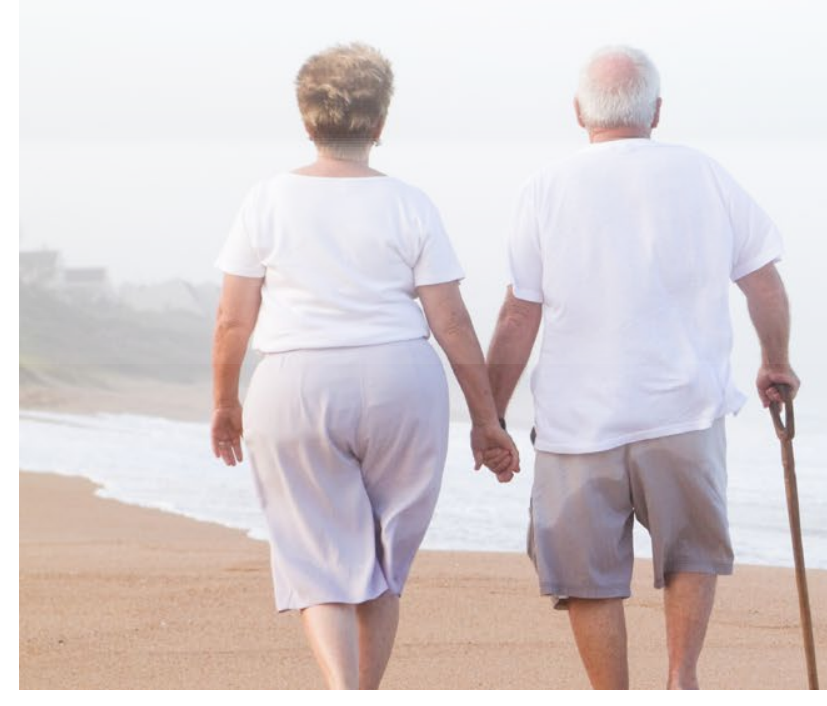

\section{References}

Hougaard Jensen, S.E., Pedersen, T.M. \& Foxman, T.B. (2019). Experiences with Occupational Pensions in Denmark, Vierteljahrshefte zur Wirtschaftsforschung / Quarterly Journa Economic Research, 88(1) 11-30.

Hougaard Jensen, S.E., Sveinsson, T.S. \& Zoega, G. (2019). Longevity, Retirement and Intra-Generational Equity, CESifo Working Paper Series 7704, CESifo Group Munich.

Hougaard Jensen, S.E., \& Jørgensen, O. (2008). Uncertain demographics, longevity adjustment of the retirement age $J$. and intergenerational risk-sharing. In: J. Alho, S. Jensen, \& J. Lassila (Eds.), Uncertain Demographics and Fiscal Sustainability. Cambridge: Cambridge University Press, 239-257.

Hougaard Jensen, S.E., Sveinsson, T.S. \& Vieira, F.B. (2019), Reform and Backlash to Reform: Longevity Adjustment of the Retirement Age. Chapter 3 in "Essays on Pensions and Fiscal Sustainability", PhD thesis submitted by Filipe Vieira Copenhagen Business School, December 2019.

\section{Personal Response} What is the most pertinent piece of advice you would
give to policy makers involved in retirement reform?

II Linking the retirement age to changes in longevity is critical tor fiscal sustainability. However, the adverse
effect on the shorter lived groups is magnified when the retirement age is explicitly linked to average life expectancy. The unintended distributional effects may then jeopardise the egalitarian objectives typically reduces the lifetime utility of say, blue-collar workers with health issues due to a long working life with physically demanding work, the broad political support behind longevity adjustment might well gradually disappear. This is why it is so important to remedy
these inequalities. 